\title{
Lexical processing of vocabulary class in patients with Broca's aphasia: an event-related brain potential study on agrammatic comprehension
}

\author{
Mariken ter Keurs ${ }^{\mathrm{a}, \mathrm{b}}$, Colin M. Brown ${ }^{\mathrm{a}}$, Peter Hagoort ${ }^{\mathrm{a}, \mathrm{c}, *}$ \\ ${ }^{a}$ Neurocognition of Language Processing Research Group, Max Planck Institute for Psycholinguistics, Nijmegen, The Netherlands \\ ${ }^{\mathrm{b}}$ Department of Clinical Neurophysiology, Institute of Neurology, University Hospital Nijmegen, Nijmegen, The Netherlands \\ ${ }^{c}$ F.C. Donders Centre for Cognitive Neuroimaging, P.O. Box 9101, 6500 HB, Nijmegen, The Netherlands
}

Received 13 July 2001; received in revised form 25 January 2002; accepted 25 January 2002

\begin{abstract}
This paper presents electrophysiological evidence of an impairment in the on-line processing of word class information in patients with Broca's aphasia with agrammatic comprehension. Event-related brain potentials (ERPs) were recorded from the scalp while Broca patients and non-aphasic control subjects read open- and closed-class words that appeared one at a time on a PC screen. Separate waveforms were computed for open- and closed-class words. The non-aphasic control subjects showed a modulation of an early left anterior negativity in the 210-325 ms as a function of vocabulary class (VC), and a late left anterior negative shift to closed-class words in the 400-700 ms epoch. An N400 effect was present in both control subjects and Broca patients. We have taken the early electrophysiological differences to reflect the first availability of word-category information from the mental lexicon. The late differences can be related to post-lexical processing. In contrast to the control subjects, the Broca patients showed no early VC effect and no late anterior shift to closed-class words. The results support the view that an incomplete and/or delayed availability of word-class information might be an important factor in Broca's agrammatic comprehension. (C) 2002 Elsevier Science Ltd. All rights reserved.
\end{abstract}

Keywords: Broca's aphasia with agrammatic comprehension; Language; Closed-class words; Open-class words; Event-related brain potential; Lexical processing

\section{Introduction}

In this study we pursued our investigations of the electrophysiological manifestations of vocabulary class (VC) in patients with Broca's aphasia with agrammatic comprehension, as reflected by scalp-recorded event-related brain potentials (ERPs). We focused on the role of the on-line lexical stages of VC processing in agrammatic comprehension.

Although certainly not unchallenged (see [16] for an extensive review), a specific impairment in the processing of closed-class words has been claimed in several accounts on agrammatic comprehension (e.g. [2,3,7-9,28,30,35]). In a previous study [14] we investigated whether Broca patients' agrammatic comprehension might be related to an impairment in the processing of closed-class words, by investigating electrophysiological manifestations of on-line processing of open- and closed-class words. ERPs were recorded from the scalp while Broca patients and non-aphasic control subjects were visually presented with

\footnotetext{
* Corresponding author. Tel.: +31-24-3610651; fax: +31-24-3610652

E-mail addresses: terkeurs.dewit@consunet.nl, peter.hagoort@fcdonders.kun.nl (P. Hagoort).
}

a story in which the words appeared one at a time on a computer screen. A story-context was chosen to allow closed-class items to play their full functional (syntactic) role in sentence comprehension. Separate waveforms were computed for open- and closed-class words.

The most relevant finding of this study was that whereas non-aphasic control subjects showed clear differences in the electrophysiological profiles elicited by open- and closed-class words between approximately 210 and $375 \mathrm{~ms}$ after a word appeared on screen, Broca patients with agrammatic comprehension did not.

Early differences in the electrophysiological profiles elicited by open- and closed-class items in non-aphasic subjects have been related to the early stages of word processing in which the lexical-syntactic and the lexical-semantic information of a word is accessed and made available for further (sentential) processing $[4,15,21,23,27]$. The differences consist of differences in the amplitude and/or latency of a negativity elicited between approximately 200 and $375 \mathrm{~ms}$ by both open- and closed-class words $[4,14,15,21,23,24,26,27,29]$. Which particular stage of lexical processing is reflected awaits further research, but the absence or presence of an effect of lexical-statistical factors 
such as word frequency and/or length on the early electrophysiological differences, has played an important role in the functional interpretations of the differences. In some studies (e.g. [15,26,27] and sentence results from [21]) the latency of the early negativity, elicited by both open- and closed-class items, was found to vary as a function of both word frequency and length. However, in other studies including our own $[4,14,21,23]$ neither word frequency nor length had an effect on either the elicitation or the morphology of the early electrophysiological differences. This makes it less likely that these early differences are related to prelexical or initial stages of lexical processing, such as lexical access. Hence, we have interpreted the early differences in the non-aphasic control subjects as the earliest manifestation of the availability of word-category information from the mental lexicon.

The striking finding that the Broca patients with agrammatic comprehension did not show these early differences in the electrophysiological profiles elicited by open- and closed-class words has important implications. It suggests that these patients already show impairment at the level of the on-line lexical processing of VC. Irrespective of the particular lexical stage at which this impairment originates, this deficit might seriously affect successful on-line sentence processing. Both the full availability of lexical-categorical information and its availability at the right moment in time are important prerequisites for successful on-line sentence processing. Although our previous study set out to investigate whether Broca patients with agrammatic comprehension have an impairment in the processing of closed-class words, no evidence was found for an impairment restricted to the processing of closed-class words only. The electrophysiological profiles elicited by the open- and closed-class words in the Broca patients showed an early negative response in both waveforms, it simply did not differ as a function of VC.

Not only in the early epoch, but also in a later time epoch did the Broca patients with agrammatic comprehension show electrophysiological evidence for abnormal processing of VC. The Broca patients showed only a very reduced effect in a late $400-700 \mathrm{~ms}$ epoch over anterior sites, where control subjects showed a clear effect. The sustained negative shift over anterior sites in the 350-700 ms latency range that is seen in normal control subjects to closed-class words $[4,15,17,21-24,26,27,29,33]$ has been related to post-lexical processing of syntactic information.

Another difference in the waveforms between the VCs has been related to semantic processing $[4,14,17,21-23,27,29]$. This is that open-class words elicit a larger N400 than closed-class words.

In short, assuming that the early differences in the electrophysiological profiles elicited by open- and closed-class words indeed reflect differences in the lexical processing of $\mathrm{VC}$, the absence of these differences in Broca patients with agrammatic comprehension is an important finding with implications for accounts of agrammatic comprehension.

In the present study, we want to add to the electrophysiological evidence suggesting that Broca patients with agrammatic comprehension show an impairment in on-line lexical processing. We will do this by investigating electrophysiological manifestations of on-line processing of openand closed-class words when presented in isolation, thus without a sentential or lexical context.

The differences between Broca patients with agrammatic comprehension and control subjects in the lexical processing of VC, as found in our previous study [14] should be independent of whether the open- and closed-class words are presented in isolation or in the context of prose. Hence, the absence of a difference in the early negativity (between approximately 200 and $375 \mathrm{~ms}$ ) between open- and closed class words that we observed for Broca patients in a condition where sentence-level processing was required, should also show up in a condition where only word-level processing is required. Presentation of words in isolation will furthermore allow us to evaluate to what extent late (post-lexical) differences in the processing of VC between Broca patients and control subjects depend on context.

\section{Methods}

\subsection{Subjects}

Thirteen patients with aphasia secondary to a single CVA in the left hemisphere participated in this study. A group of 12 healthy normal subjects, who were approximately matched in age and education to the aphasic patients, were tested to control for age and education effects. To account for non-specific effects of brain damage on cognitive ERP-components, a group of eight non-aphasic patients with a single CVA in the right hemisphere (RH patients) was tested. All subjects gave informed consent, according to the declaration of Helsinki. The mean age of the aphasic patients was 60.9 years (range $41-77$ years), the RH patients had a mean age of 60.8 years (range 49-70 years), and the normal controls were on average 57.9 years old (range 50-69 years). All subjects had normal or corrected-to-normal vision, and were (premorbidly) right-handed according to an abridged Dutch version of the Oldfield Handedness Inventory [25]. All neurological patients were tested at least 9 month post-onset of their CVA. Median post-onset time was 3.6 years (range $0.8-12$ years) for the RH patients, and 8.5 years (range 2.4-19.5 years) for the Broca patients.

All neurological patients were tested with the standardized Dutch version of the Aachen aphasia test (AAT) [10]. Both presence and type of aphasia were diagnosed on the basis of the AAT results and on the basis of a transcribed sample of the patient's spontaneous speech. The patient's spontaneous speech was evaluated by three experts. All RH patients were diagnosed as non-aphasic and all left-hemisphere patients were diagnosed as Broca patients on the basis of a procedure that matches the individual score profiles against a norm population of patients. According to their scores on the comprehension subtest of the AAT, the aphasic patients had severe 
to mild comprehension deficits. Agrammatic comprehension was determined by administering all subjects the Dutch version of an off-line test which assesses the influence of syntactic complexity on sentence comprehension [13] (see [14] for a detailed description of the Dutch version). One RH patient had a relatively low score on the syntactic off-line test. On the basis of her spontaneous speech and AAT results, this patient was clearly non-aphasic. On the syntactic off-line test, in which subjects had to select out of four pictures the one that matched the auditorily presented sentence, this patient did not show the syntactic complexity effect that was seen in the Broca patients. In contrast to the aphasic patients and in line with the normal controls, her score on syntactically more complex sentences was no different from her score on syntactically simple sentences. This implies that her relatively poor performance on the syntactic off-line test was not due to a syntactic impairment, but most likely to problems of visual attention. Statistical evaluation of the syntactic off-line test results confirm the syntactic comprehension problems of the Broca patients as compared to the normal controls and the RH control patients. The Broca patients can therefore be classified as agrammatic comprehenders.

Patients' age, gender, results on the token test, scores on the AAT-subtest on comprehension, overall scores on the syntactic off-line test, and lesion site information are summarized in Table 1.

\subsection{Stimuli}

The open- and closed-class stimuli that were visually presented in the context of a story in our previous study [14] were edited for presentation in isolation in the present experiment. All items that were syntactically ambiguous in isolated presentation were either replaced by their syntactically unambiguous form or excluded from the stimulus set. In total, a set of 703 words was presented, consisting of 330 open-class words (142 nouns, 122 verbs, 66 adjectives), and 373 closed-class words (212 articles, 98 prepositions, 63 conjuncts).

The open-class words ranged in length from 3 to 12 letters, the closed-class words from 2 to 7 letters. Frequency of occurrence was between 0.0 and 4.2 on a $\log$ frequency scale (i.e. 1-15.849 per million) for the open-class words and between 2.6 and 4.9 (i.e. 398-79.432 per million) for the closed-class words. The frequencies were obtained from a Dutch frequency-coded corpus based on over 42 million tokens [1].

As the open- and closed-class stimuli were originally drawn from a natural text in which words were repeated as a consequence of normal discourse structure, the stimuli consist both of new words (words that had not previously occurred) and of single or multiple repetitions of these new words. It is an inherent property of natural language

Table 1

Individual patient information for the Broca patients and the non-aphasic RH control patients

\begin{tabular}{|c|c|c|c|c|c|c|c|}
\hline Patient & $\begin{array}{l}\text { Age } \\
\text { (years) }\end{array}$ & Sex & $\begin{array}{l}\text { Token } \\
\text { test }^{\mathrm{a}}\end{array}$ & $\begin{array}{l}\text { Overall compre- } \\
\text { hension score } \mathrm{AAT}^{\mathrm{b}}\end{array}$ & $\begin{array}{l}\text { Visual compre- } \\
\text { hension score AAT }\end{array}$ & $\begin{array}{l}\text { Syntactic off- } \\
\text { line score }\end{array}$ & Lesion site \\
\hline 1 Broca & 77 & Female & 7 & $108 / 120$ & $56 / 60$ & $115 / 144$ & Left frontal \\
\hline 2 Broca & 41 & Male & 29 & $67 / 120$ & $28 / 60$ & $60 / 144$ & Left frontotemporoparietal \\
\hline 3 Broca & 66 & Female & 18 & $91 / 120$ & $45 / 60$ & $111 / 144$ & Left frontotemporoparietal \\
\hline 4 Broca & 52 & Female & 10 & $97 / 120$ & $49 / 60$ & $95 / 144$ & Left frontotemporoparietal \\
\hline 5 Broca & 72 & Male & 46 & $90 / 120$ & $44 / 60$ & $59 / 144$ & Left frontotemporoparietal \\
\hline 6 Broca & 50 & Male & 42 & $89 / 120$ & $44 / 60$ & $51 / 144$ & Left temporoparietal \\
\hline 7 Broca & 64 & Female & 45 & $65 / 120$ & $34 / 60$ & $44 / 144$ & Left frontotemporal \\
\hline 8 Broca & 45 & Male & 17 & $94 / 120$ & $49 / 60$ & $74 / 144$ & Left temporoparietal \\
\hline 9 Broca & 66 & Male & 38 & $67 / 120$ & $28 / 60$ & $52 / 144$ & Left frontotemporal \\
\hline 10 Broca & 66 & Male & 33 & $82 / 120$ & $50 / 60$ & $28 / 144$ & Left temporal \\
\hline 11 Broca & 67 & Female & 11 & $103 / 120$ & $50 / 60$ & $90 / 144$ & Left frontoparietal \\
\hline 12 Broca & 58 & Male & 35 & $87 / 120$ & $46 / 60$ & $80 / 144$ & No CT information available \\
\hline 13 Broca & 66 & Male & 24 & $85 / 120$ & $42 / 60$ & $92 / 144$ & Left frontotemporal \\
\hline $1 \mathrm{RH}$ & 49 & Male & 0 & $113 / 120$ & $56 / 60$ & $134 / 144$ & No CT information available \\
\hline $2 \mathrm{RH}$ & 60 & Male & 1 & $117 / 120$ & $60 / 60$ & $134 / 144$ & Right frontotemporal \\
\hline $3 \mathrm{RH}$ & 70 & Female & 2 & $106 / 120$ & $53 / 60$ & $89 / 144$ & Right frontoparietal \\
\hline $4 \mathrm{RH}$ & 67 & Female & 2 & $102 / 120$ & $54 / 60$ & $118 / 144$ & Right parietal \\
\hline $5 \mathrm{RH}$ & 53 & Male & 9 & $106 / 120$ & $55 / 60$ & $128 / 144$ & Right frontoparietal \\
\hline $6 \mathrm{RH}$ & 51 & Male & 0 & $104 / 120$ & $53 / 60$ & $130 / 144$ & Right frontotemporal intracerebral \\
\hline $7 \mathrm{RH}$ & 64 & Male & 2 & $116 / 120$ & $56 / 60$ & $137 / 144$ & Right parietal intracerebral \\
\hline $8 \mathrm{RH}$ & 69 & Female & 0 & $117 / 120$ & $60 / 60$ & $138 / 144$ & Right capsula interna \\
\hline
\end{tabular}

\footnotetext{
${ }^{a}$ Severity of the aphasia as indicated by the token test: no/minimal disorder (0-6); light (7-23); middle (24-40); severe (41-50).

${ }^{\mathrm{b}}$ Severity of the comprehension disorder as indicated by the AAT subtest on comprehension (includes word and sentence comprehension in both auditory and visual modality): no/very mild disorder (107-120); light (90-106); middle (67-89); severe (1-66).

${ }^{c}$ ANOVAs on the percentage-correct scores of the sentences with increasing syntactic complexity of the off-line test showed that syntactic complexity had a differential effect on the comprehension scores of the different subject groups (complexity: $F=34.33, P<0.0001 ;$ complexity $\times$ group: $F=6.33$, $P<0.0001$ ), with the Broca patients performing significantly worse than both the normal controls and the RH control patients. The two control groups did not differ significantly from each other.
} 
that closed-class items are few and often repeated, whereas open-class items are many and less often repeated. The set of open-class stimuli contained $79 \%$ new words, $16 \%$ single repetitions and 5\% multiple repetitions (nouns: new 86\%; verbs: new 70\%; adjectives: new 83\%). The set of closed-class stimuli contained 5\% new words (articles: new $1 \%$ (there are only three articles in Dutch); prepositions: new $12 \%$; conjuncts: new 5\%), $0.5 \%$ single repetitions, and $94.5 \%$ multiple repetitions (range 2-108 repetitions). Word repetition (open-class) primarily seems to affect the amplitude of the N400 in the ERP response and the positivity in the late part of the waveform (see e.g. [32,34] for reviews). Since the primary focus of this study is in comparing Broca patients to their controls, possible repetition effects are not of central interest, and therefore not evaluated separately.

\subsection{Procedure}

All the subjects were tested in a quiet room. The words were presented in four semi-randomized blocks under the constraint that no more than three content words and no more than five closed-class words directly followed each other. The number of items between the presentation of a new word and its single or multiple repetition (inter-item lag) varied over VC. There were no direct repetitions for either word class. For $79 \%$ of the single repetitions of the open-class words, the inter-item lag was more than a block (>4 min). For the remaining $21 \%$, the lag varied between 1 and 112 items. The inter-item lag varied for $97 \%$ of the closed-class repetitions from 1 to 200 items, while for $3 \%$ the lag was more than $4 \mathrm{~min}$, as repetitions were presented over blocks. Each block started with five filler items. Each word was presented visually for $400 \mathrm{~ms}$ in a $10 \mathrm{~cm} \times 2.5 \mathrm{~cm}$ window on a high-resolution PC screen that was covered by a black non-reflecting shield. Each word was followed by a $400 \mathrm{~ms}$ blank-screen interval (i.e. the stimulus-onset asynchrony was $800 \mathrm{~ms}$ ). After the presentation of a variable number of words (on average 10, range 4-16 words), a 2200 ms blank-screen interval occurred marked with a star. Subjects were instructed to blink during the presence of the star and to refrain from blinking in the remaining period. All the words were written in lower case. Viewing distance was between 70 and $80 \mathrm{~cm}$, and the stimuli subtended a vertical visual angle of approximately $3^{\circ}$.

The blocks were presented over subjects in a balanced Latin square. A practice block to familiarize the subjects with the experimental procedure preceded the blocks. A session lasted approximately one and a half-hours, including electrode application and removal.

Subjects were instructed to read each word carefully, with no additional task. They were also instructed to move as little as possible, and to keep their eyes fixated on the window in the center of the screen. To make sure that the subjects were actually reading the words, the experimenter would at various moments during the breaks between the list presentations ask the subjects several questions about the words (e.g. about their visibility, context, etc.).

\subsection{EEG recording}

Continuous EEG was recorded from 27 tin electrodes attached to an electrode cap, each referred to the left mastoid. Activity over the right mastoid was actively recorded on a separate channel to determine whether there were any differential effects of the experimental variables on the mastoid recordings. No such effects were observed. Sixteen electrodes (F7, F8, Fz, F3, F4, T3, T4, C3, C4, T5, T6, P3, $\mathrm{P} 4, \mathrm{Pz}, \mathrm{O} 1$ and $\mathrm{O} 2$ ) were placed according to the international 10-20 system. Eleven electrodes were placed over non-standard intermediate sites $\left(\mathrm{Fz}^{\prime}, \mathrm{Tf} 1, \mathrm{Tf} 2, \mathrm{Tfc} 1, \mathrm{Tfc} 2\right.$, $\mathrm{Fc} 1, \mathrm{Fc} 2$, Tpc1, Tpc2, Pc1 and Pc2). Vertical and horizontal eye movements were monitored bipolarly via sub- and supra-orbital electrodes, and left and right external canthal montages, respectively. The ground electrode was placed on the standard midline central site $\mathrm{Cz}$.

The EEG and EOG recordings were amplified by a Neurotop MME-3100 multi-channel bio-electric amplifier system, using a band-pass filter of $0.016-35 \mathrm{~Hz}$. Impedances were kept below $5 \mathrm{k} \Omega$. The EEG signal was digitized on-line by a BEST recording system with a sample frequency of $200 \mathrm{~Hz}$.

\subsection{EEG analysis}

Trials that were contaminated by eye movements, muscular activity, excessive electrode drift, or amplifier saturation were removed, first by an automatic procedure, and subsequently on visual inspection by a manual procedure prior to averaging. For the 12 normal control subjects, $35 \%$ of the trials were removed prior to averaging, evenly divided over the open- and closed-class items. For the 13 Broca patients, in total $41 \%$, and for the eight RH patients, in total $44 \%$ of the trials were removed, again for both groups evenly divided over the open- and closed-class items. The differences in rejection rates were not significant.

In the analyses reported later, different subsets of electrodes were taken together to investigate the topographical distribution of the ERP effects. For purposes of brevity, we use the following labels: anterior left (AL; F7, F3, TfC1 and $\mathrm{Fc} 1$ ), anterior right (AR; F8, F4, TfC2 and $\mathrm{Fc} 2$ ), anterior $(\mathrm{AL}+\mathrm{AR})$, posterior left (PL; TpC1, Pc1, T5 and P3), posterior right (PR; TpC2, $\mathrm{Pc} 2, \mathrm{~T} 6$ and $\mathrm{P} 4)$, posterior $(\mathrm{PL}+\mathrm{PR})$, left $(\mathrm{AL}+\mathrm{PL})$ and right $(\mathrm{AR}+\mathrm{PR})$.

On the basis of visual inspection of the waveforms of the different subject groups, four latency windows were selected for statistical analysis: 125-200, 210-325, 325-550 and $400-700 \mathrm{~ms}$. These time epochs roughly correspond to the latency ranges of the $\mathrm{P} 2$, the early and late differences in processing of $\mathrm{VC}$, and are consistent with previous reports, including our own. Analyses were performed on the mean amplitude values in the specified time-windows. Mean amplitude was determined via a computerized procedure. 
First, for each subject the waveform elicited by each word was normalized with respect to the averaged activity in a $100 \mathrm{~ms}$ baseline preceding the stimulus. Then, in selected epochs, the mean amplitude was computed in the waveform for each electrode, for each VC, for each subject. The resulting values were entered into repeated measures analyses of variance (ANOVA) with VC (open-class versus closed-class) and electrode site as within-subjects factors. The Huyn-Feldt correction was applied when evaluating effects with more than $1^{\circ}$ of freedom in the numerator [19]. The adjusted degrees of freedom and $P$-values will be reported. Effects involving the factor electrode site are only reported for significant interactions with VC. For these interactions, ANOVA were computed after performing a Z-score normalization procedure to equalize the overall mean amplitudes across experimental conditions. This procedure is described by Rösler et al. [31] and is equivalent to the normalization procedure suggested by McCarthy and Wood [20].

To directly test for differences between the results for the control groups and the Broca patients, group analyses were performed in the specified time-windows over restricted electrode sites. Repeated measures ANOVA were performed with VC as a within-subjects factor and group (controls, Broca patients, RH patients) as a between subjects factor.

Given the concurrence of lexical-statistical factors and word class (closed-class words are in general shorter and more frequent), we also tested in each subject group whether the observed differences in the $210-325 \mathrm{~ms}$ epoch could be attributed to lexical frequency and length rather than to $\mathrm{VC}$. We approached this issue by performing mean-amplitude analyses collapsing over all word types (i.e. ignoring VC), in which we compared waveforms that were averaged as a function of different frequency ranges, keeping word length constant, or as a function of different lengths, keeping frequency constant. The rationale behind this approach is that if the different early negative effects for the two VCs are related to lexical statistical factors, these differences should also emerge when the data are averaged as a function of lexical statistical factors (see also [4,14]).

\section{Results}

Figs. 1-3 show the grand average waveforms for the openand closed-class category as measured over the respective electrode sites, for the 12 normal control subjects, the eight $\mathrm{RH}$ control patients, and the 13 Broca patients with agrammatic comprehension, respectively. Fig. 4 shows the difference in mean amplitude between closed- and open-class words for the three subject groups for the different time epochs over restricted electrode sites. For presentation purposes, the EEG-data in the figures have been smoothed over $20 \mathrm{~ms}$ intervals. Tables $2-4$ show the relevant statistical results for the different time epochs.

\subsection{P2 effects: $125-200 \mathrm{~ms}$}

Following the early visual components, a P2 component is elicited by both VCs in all three subject groups (Figs. 1-3). All the subject groups showed significantly reduced P2 amplitude for the closed-class words $(F(1,30)=61.79, P<$ $0.0001)$ over anterior sites. No interactions between VC and group were found.

\subsection{Early vocabulary class differences: $210-325 \mathrm{~ms}$}

\subsubsection{Normal control subjects}

In an early time epoch, between approximately 210 and $325 \mathrm{~ms}$, a clear negativity is elicited by the closed-class words (Fig. 1). It peaks at about $260 \mathrm{~ms}$, has a predominant anterior distribution, and is larger over the left than the $\mathrm{RH}$. The open-class words also elicit a negativity, which is maximal over anterior sites, peaking at the same latency as the closed-class words, but of reduced amplitude.

As can be seen in Table 2, statistical analysis corroborates these observations. Overall analyses on the mean amplitudes in this latency range did not show a significant overall effect of $\mathrm{VC}$, but topographical analyses demonstrated a VC effect over anterior sites, with a significantly reduced amplitude for the open-class words. The effect is largest over left anterior sites.

\subsubsection{Non-aphasic RH control patients}

Just like in the normal control subjects, the closed-class words elicit a negative-going waveform between approximately 210 and $325 \mathrm{~ms}$, with a predominantly anterior distribution (Fig. 2). Over left anterior sites the waveforms show a biphasic morphology, whereas over right anterior sites a peak is visible at about $240 \mathrm{~ms}$. In the same epoch, the open-class words also elicit a negative-going waveform with the same peak latency, but of reduced amplitude. This negativity is more prominent over right anterior sites. The mean amplitude difference between the two VCs is significant and largely restricted to left anterior sites.

\subsubsection{Broca patients with agrammatic comprehension}

The ERP profiles elicited by the open- and closed-class vocabulary in the $210-325 \mathrm{~ms}$ epoch in the Broca patients show both divergences and commonalities with the waveforms elicited by the two groups of control subjects (Fig. 3). As in the control subjects, a negativity with a predominantly anterior distribution is elicited by both open- and closed-class words. However, in contrast to both groups of control subjects there is no modulation of this negativity as a function of VC. The negativity is of approximately equal amplitude for the two VCs and for both classes, peaks at about $260 \mathrm{~ms}$.

\subsubsection{Group analyses}

Given that the VC effect in the $210-325 \mathrm{~ms}$ epoch was largest over left anterior sites in the group of normal controls 

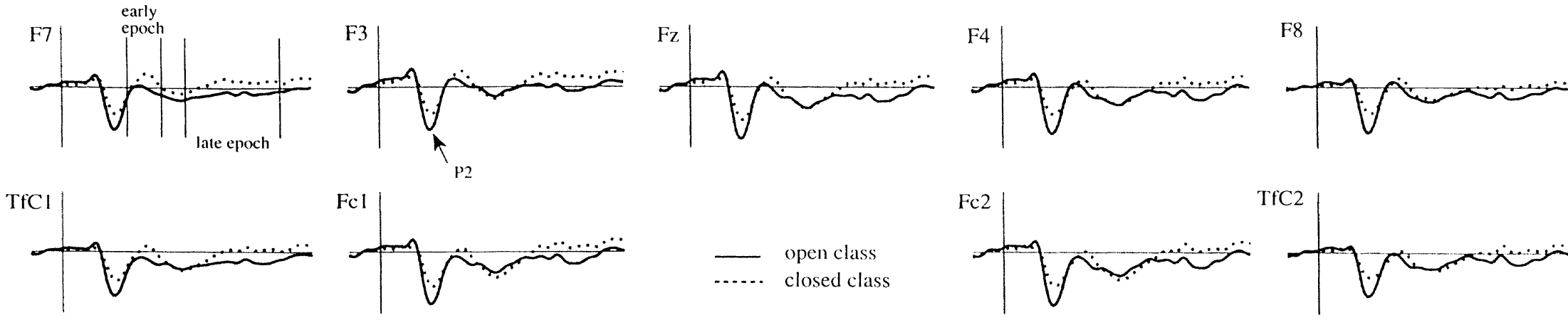

_ open class
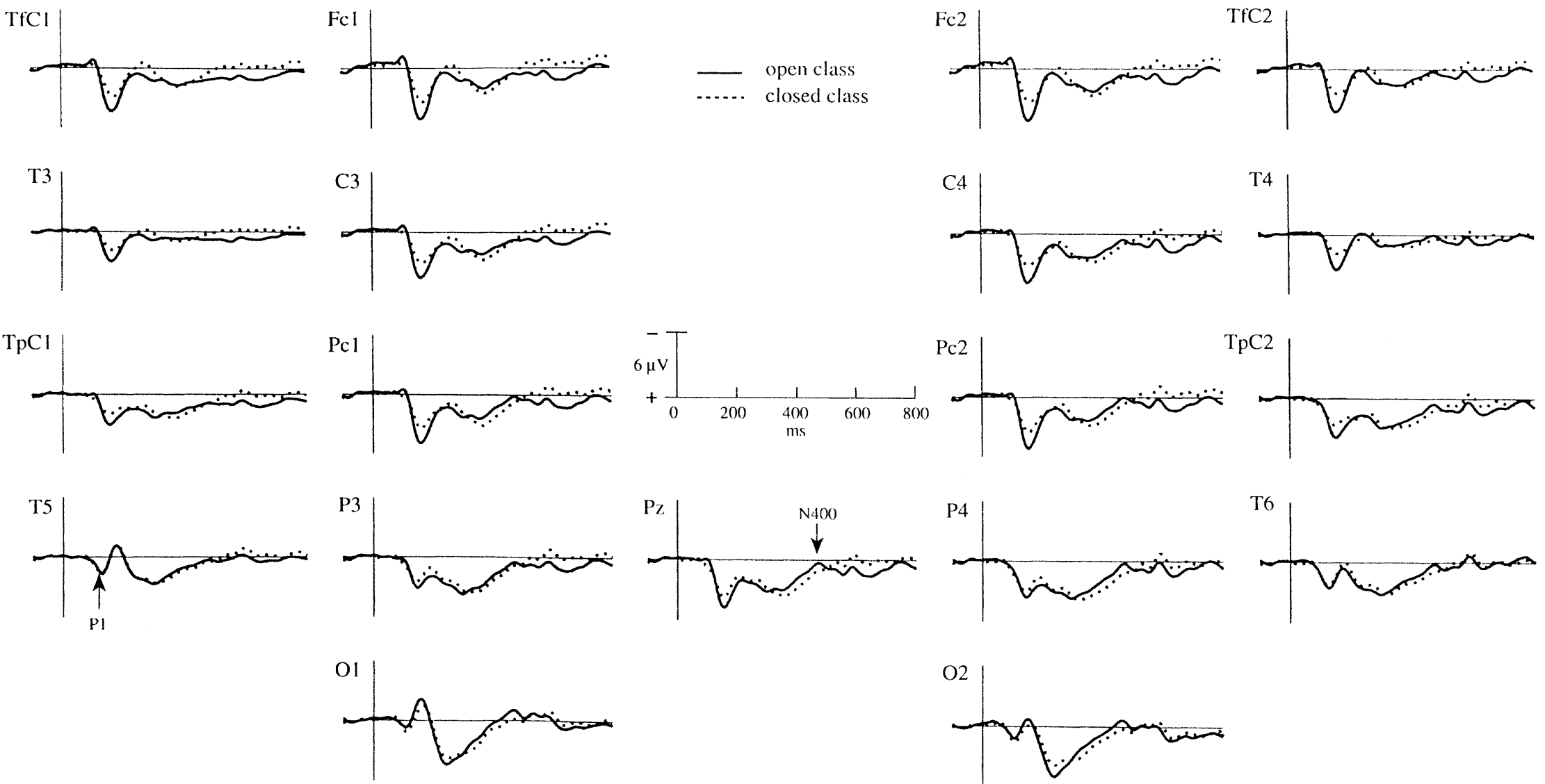

Fig. 1. Grand average waveforms elicited by the open- and closed-class categories for the group of normal control subjects $(n=12)$. Negativity is plotted upwards. The total epoch is 900 ms long, starting $100 \mathrm{~ms}$ before a word was presented. The stimulus appeared at $0 \mathrm{~ms}$ and disappeared at $400 \mathrm{~ms}$ 

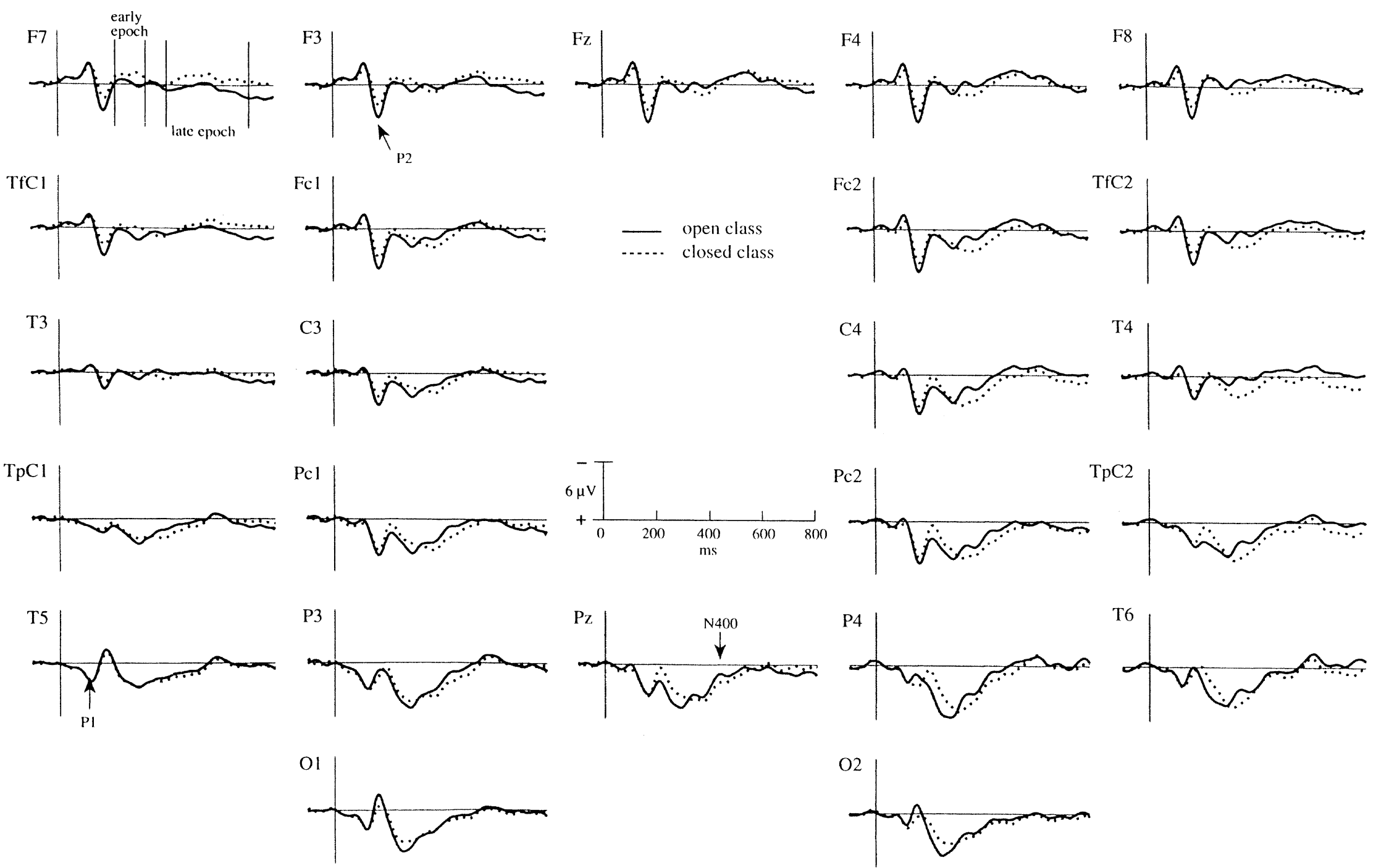

Fig. 2. Grand average waveforms elicited by the open- and closed-class categories for the group of non-aphasic RH patients $(n=8)$. Negativity is plotted upwards. The total epoch is $900 \mathrm{~ms}$ long, starting $100 \mathrm{~ms}$ before a word was presented. The stimulus appeared at $0 \mathrm{~ms}$ and disappeared at $400 \mathrm{~ms}$. 

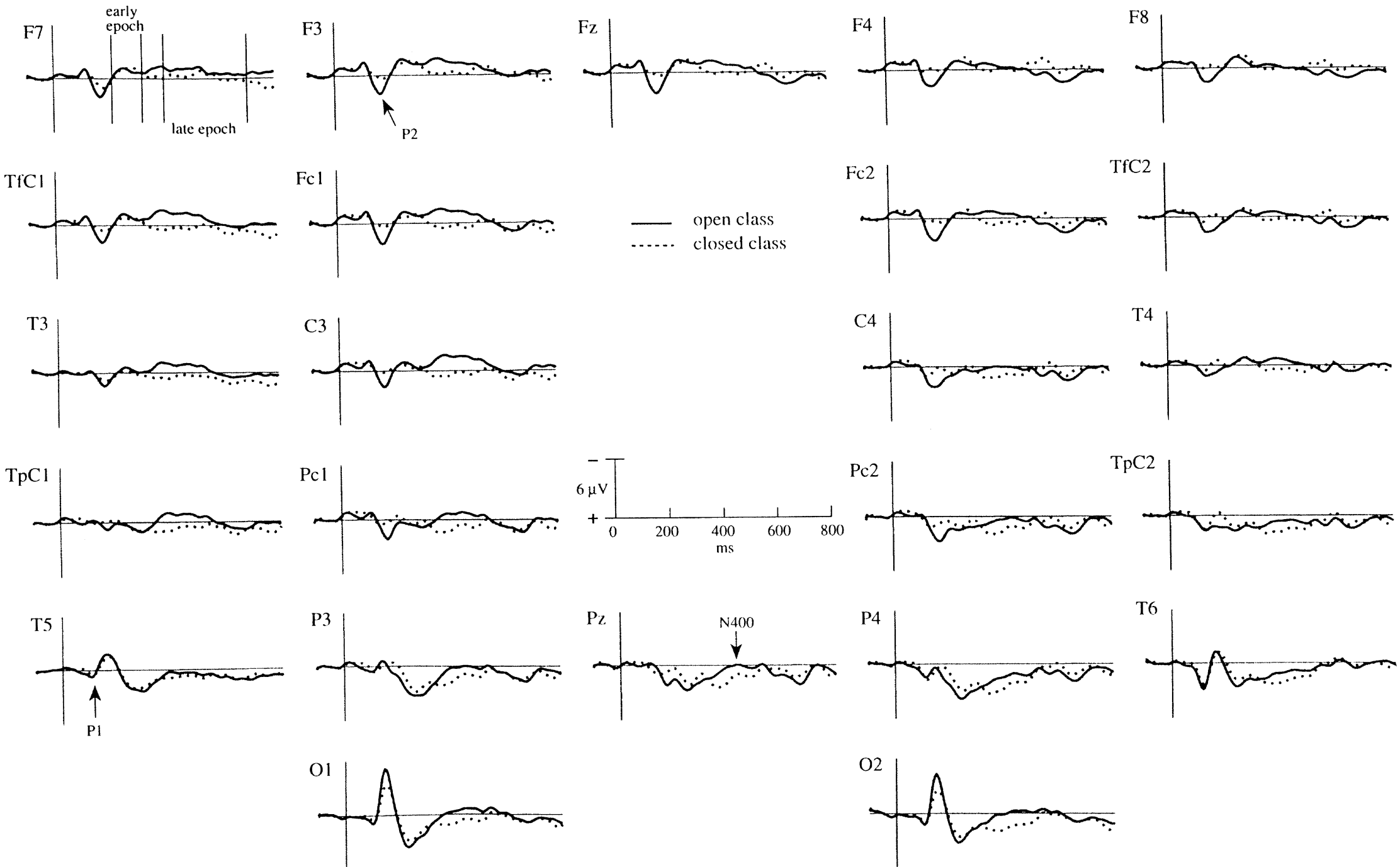

Fig. 3. Grand average waveforms elicited by the open- and closed-class categories for the group of Broca patients with agrammatic comprehension $(n=13)$. Negativity is plotted upwards. The total epoch is $900 \mathrm{~ms}$ long, starting $100 \mathrm{~ms}$ before a word was presented. The stimulus appeared at $0 \mathrm{~ms}$ and disappeared at $400 \mathrm{~ms}$. 
Normal Controls $\square$ RH control patients $\square$ Broca patients

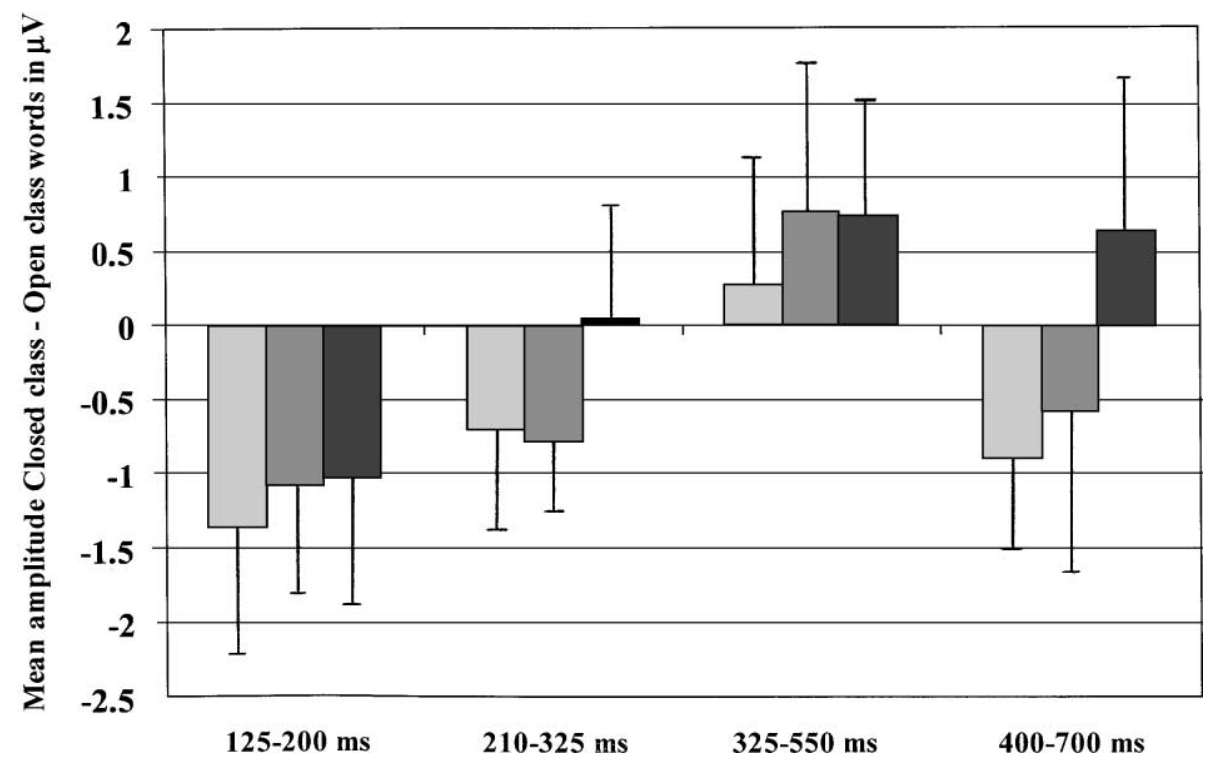

Fig. 4. Mean amplitude difference (and S.D.) between the closed- and open-class categories for the three subject groups over left anterior sites (F7, F3, TfC1 and Fc1) for the following time epochs: 125-200, 210-325 and 400-700 ms. Mean amplitude difference (and S.D.) over posterior sites (TpC1, Pc1, T5, P3, TpC2, Pc2, T6 and P4) for time epoch 325-550 ms.

and largely restricted to left anterior sites in the group of non-aphasic RH patients, the analyses comparing the different subject groups were restricted to left anterior sites. Fig. 4 shows the mean amplitude difference between the closedand open-class words in this epoch for the three subject groups over left anterior sites.

The analyses comparing the three subject groups confirmed a main effect of $\mathrm{VC}$ and a significant interaction between VC and group. Planned comparisons between the subjects groups showed that the group of Broca patients differed both from the group of normal controls and the group of RH control patients, as indicated by the significant VC-group interactions. The two control groups did not differ significantly from each other.

\subsubsection{Effects of lexical frequency and length}

Given the topography of the VC effect in the 210-325 ms epoch in the two control groups, the analyses investigating the effect of lexical frequency and length were restricted to left anterior sites. There were no clear effects of word frequency or length on the modulation of the left anterior negativity in any subject group. ${ }^{1}$

\footnotetext{
${ }^{1}$ The selection of particular lengths or frequency bins was dictated by having a sufficient number of words over which to compute an averaged potential. The maximum possible number of words in each bin ranged from 25 to 56 items per subject. After artifact rejection, on average 21 words per subject were included in each bin. In the normal control subjects, none of the analyses comparing different word lengths yielded significant effects (comparisons: frequency bin 0.2-2.0: word lengths $(4+5), 6,7,(7+8)$; frequency bin 2.2-2.8: lengths 5 and 6 ; frequency bin 3.0-3.8: lengths 3 and 4). With respect to effects of lexical frequency, analyses on all
}

\subsection{Late vocabulary class differences focusing on closed-class vocabulary: 400-700 ms}

\subsubsection{Normal control subjects}

In a late time epoch, from approximately $400 \mathrm{~ms}$ until the presentation of the next stimulus, the closed-class items elicited a broad negative shift over anterior sites, with no obvious peak (Fig. 1). The negativity is larger over left than right hemispheric sites. In a largely overlapping epoch, between approximately 325 and $550 \mathrm{~ms}$, the open-class words also elicited a negative-going waveform which, however, is most clearly visible over (right) posterior sites, and peaks at about $465 \mathrm{~ms}$. For both VCs the waveforms show an off-potential at about $550 \mathrm{~ms}$, elicited by the disappearance of the stimulus.

Analyses on the mean amplitude between 400 and $700 \mathrm{~ms}$ (Table 3), focusing on the negative shift elicited by the closed-class items confirmed the presence of a VC effect, with the closed-class words eliciting a more negative

words of lengths $(4+5)$, comparing frequency bins $0.2-2.0$ versus $2.2-2.8$ versus 3.0-3.8, and comparing the lowest and the highest frequency bin directly, yielded no significant effects. Analyses on words of length 6, comparing frequency bins $0.2-2.0$ versus $2.2-2.8$ did show an effect of frequency, with the higher frequency words associated with the smallest mean amplitude (AL, frequency: $F(1,11)=8.08, P=0.016)$. For the $\mathrm{RH}$ patients, of all the analyses on the mean amplitude in the early epoch comparing different word lengths, only the analyses comparing lengths 6 versus 8 in frequency bin $0.2-2.0$ yielded a significant effect of length (AL, length: $F(1,7)=6.13, P=0.042$ ). No effects of lexical frequency were found in the RH patients. With respect to the Broca patients, no effects of lexical frequency or word length were found. 
Table 2

ANOVA on the mean ERP amplitude in the $210-325$ ms latency range

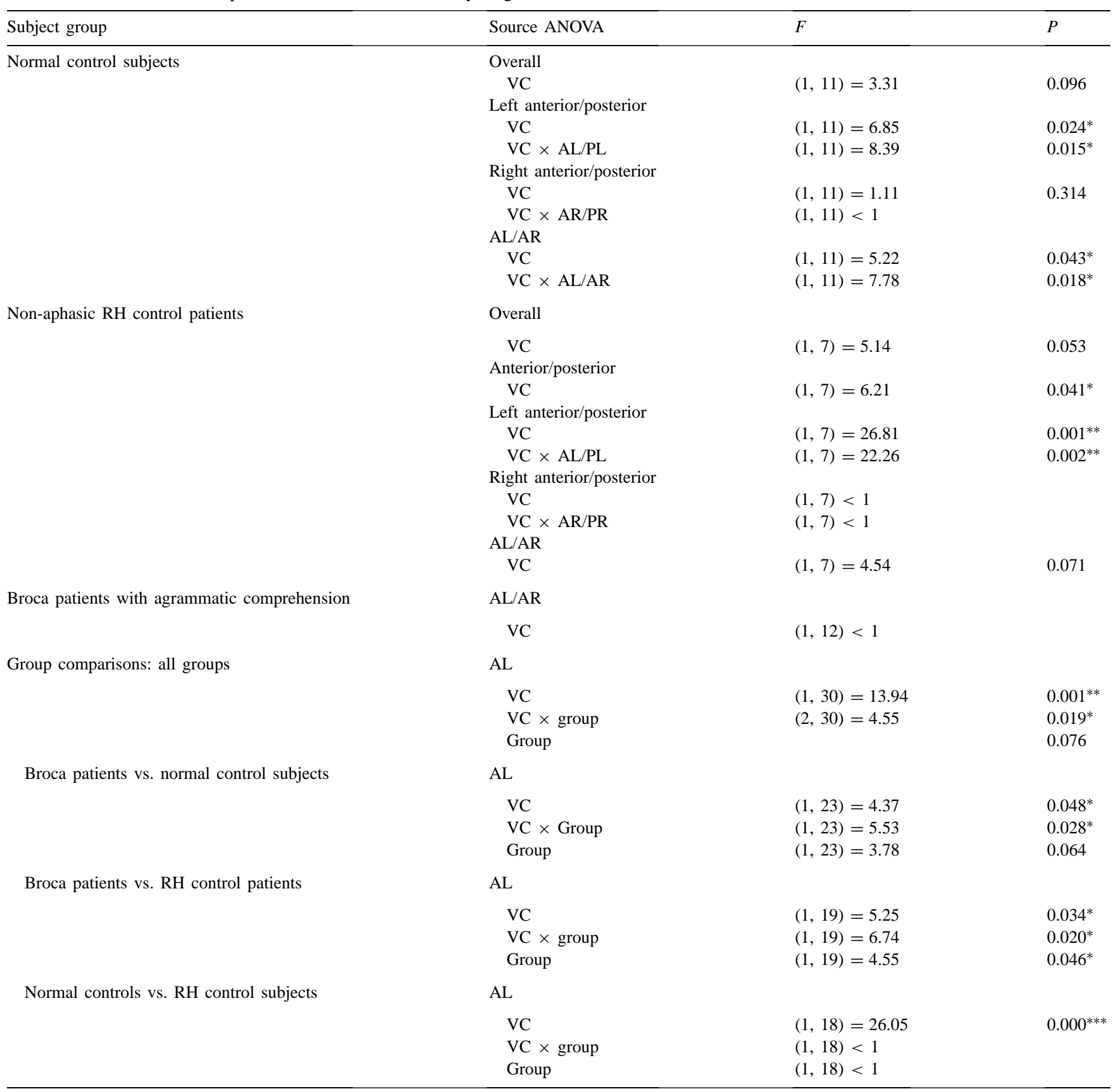

VC: vocabulary class; A: anterior; P: posterior, L: left; R: right.

$* P<0.05$

** $P<0.01$.

*** $P<0.001$

waveform than the open-class words. The effect is largest over anterior sites.

\subsubsection{Non-aphasic $R H$ control patients}

Just like in the normal control subjects, the closed-class words elicited a negativity between 400 and $700 \mathrm{~ms}$ over anterior sites in the RH patients (Fig. 2). It is of approxi- mately equal amplitude over left and right sites. As in the controls, the open-class words also elicited a negative-going waveform in a largely overlapping epoch between 325 and $550 \mathrm{~ms}$ over (right) posterior sites, with a peak at about $465 \mathrm{~ms}$. However, unlike the normal controls, a prominent negativity is also elicited by the open-class words over anterior sites. Over right anterior sites this negativity is more 
Table 3

ANOVA on the mean ERP amplitude in the $400-700 \mathrm{~ms}$ latency range

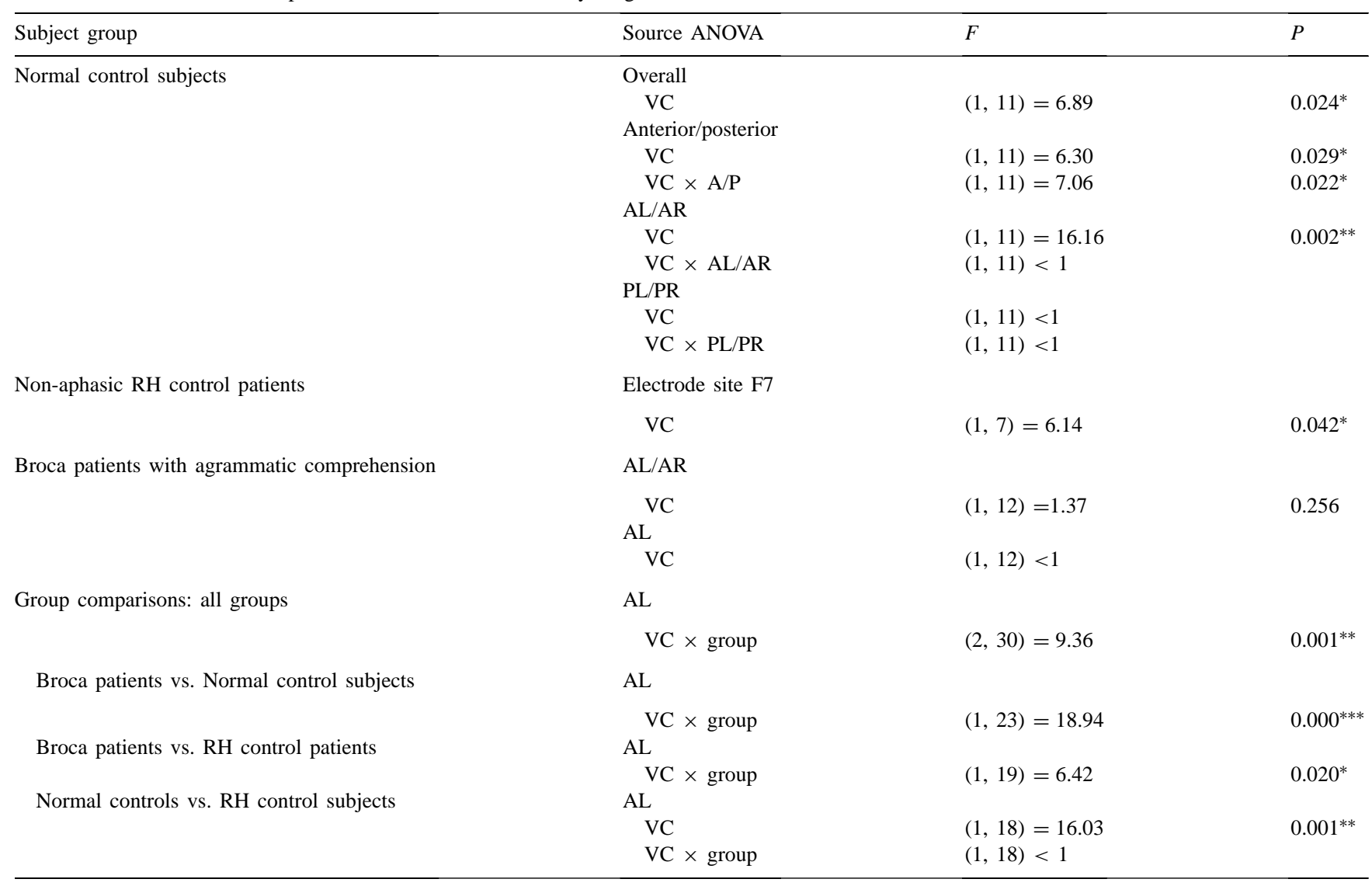

VC: vocabulary class; A: anterior; P: posterior, L: left; R: right.

${ }^{*} P<0.05$.

${ }^{* *} P<0.01$.

*** $P<0.001$.

negative than the negativity elicited by the closed-class words. Consequently, the differences in mean amplitude in the 400-700 ms epoch comparable to the differences found in the normal control subjects, are restricted to left anterior sites. These visible differences, with the closed-class words eliciting a more negative waveform than the open-class words, reached significance only over the left anterior electrode site F7.

\subsubsection{Broca patients with agrammatic comprehension}

In contrast to the control subjects, in the Broca patients no negative shift is elicited by the closed-class items in

Table 4

ANOVA on the mean ERP amplitude over PL/PR sites in the 325-550 ms latency range

\begin{tabular}{|c|c|c|c|}
\hline Subject group & PL/PR ANOVA & $F$ & $P$ \\
\hline Normal control subjects & $\begin{array}{l}\mathrm{VC} \\
\mathrm{VC} \times \mathrm{PL} / \mathrm{PR}\end{array}$ & $\begin{array}{l}(1,11)<1 \\
(1,11)<1\end{array}$ & \\
\hline Non-aphasic RH control patients & $\begin{array}{l}\mathrm{VC} \\
\mathrm{VC} \times \mathrm{PL} / \mathrm{PR}\end{array}$ & $\begin{array}{l}(1,7)=7.34 \\
(1,7)<1\end{array}$ & $0.030^{*}$ \\
\hline Broca patients with agrammatic comprehension & $\begin{array}{l}\mathrm{VC} \\
\mathrm{VC} \times \mathrm{PL} / \mathrm{PR}\end{array}$ & $\begin{array}{l}(1,12)=7.94 \\
(1,12)<1\end{array}$ & $0.039^{*}$ \\
\hline Group comparisons: all groups & $\begin{array}{l}\text { VC } \\
\text { VC } \times \text { group } \\
\text { Group }\end{array}$ & $\begin{array}{l}(1,30)=12.09 \\
(2,30)<1 \\
(2,30)<1\end{array}$ & $0.002^{* *}$ \\
\hline
\end{tabular}

VC: vocabulary class; A: anterior; P: posterior, L: left; R: right.

${ }^{*} P<0.05$.

${ }^{* *} P<0.01$. 
the 400-700 ms epoch (Fig. 3). In contrast, the open-class words elicited a clear negativity over left anterior sites, with a peak at about $380 \mathrm{~ms}$. As in both groups of control subjects, a negativity is elicited by the open-class items over posterior sites in a largely overlapping epoch between 325 and $550 \mathrm{~ms}$. Analyses over anterior sites substantiated that the VC difference over left anterior sites was absent.

\subsubsection{Group analyses: $400-700 \mathrm{~ms}$}

Given the topography of the VC effect in the control subjects we focused the group analyses on the left anterior sites (Fig. 4). This analysis resulted in a significant interaction between VC and group. Analyses of this interaction in planned comparisons between the subject groups showed that again the group of Broca patients differed from both the group of normal control subjects and the group of RH control patients. In the comparisons between the Broca patients and both control groups there was a significant interaction between $\mathrm{VC}$ and group. However, in the comparison between the control groups no interaction between $\mathrm{VC}$ and group was found. In contrast, there was a main effect of VC, with the closed-class items eliciting a more negative waveform than the open-class words.

\subsection{Late vocabulary class differences focusing on the open-class vocabulary: $325-550 \mathrm{~ms}$}

\subsubsection{Normal control subjects}

The negative-going waveform elicited by the open-class words over posterior sites peaks at about $465 \mathrm{~ms}$ and is most prominent over RH sites (Fig. 1). However, an analysis on the mean amplitude in the $325-550 \mathrm{~ms}$ range over posterior sites did not show significant effects of VC (Table 4).

\subsubsection{Non-aphasic RH control patients}

The negativity elicited by the open-class words over posterior sites peaks at $466 \mathrm{~ms}$ and is most prominent over $\mathrm{RH}$ sites (Fig. 2). The differences in mean amplitude between the two word classes over these sites are significant, with the open-class words eliciting a more negative waveform than the closed-class words. The $\mathrm{VC}$ effect is approximately equally large over left and RH sites.

\subsubsection{Broca patients with agrammatic comprehension}

Just as in both groups of control subjects, the open-class words elicited a negative-going waveform over posterior sites (Fig. 3). The differences between the two word classes are significant, with roughly equal size over both hemispheres.

\subsubsection{Group analyses: $325-550 \mathrm{~ms}$}

The analyses comparing the three subject groups in the $325-550 \mathrm{~ms}$ epoch, confirmed a main effect of VC over posterior sites, with the open-class words eliciting a consistently more negative waveform than the closed-class words
(Fig. 4). No significant differences between the different subject groups were found.

\section{Discussion}

In summary, visual processing of open- and closed-class words in isolation showed VC effects in the ERP waveforms which were maximal over left anterior electrode sites in a 125-200, 210-325 and 400-700 ms epoch, and over posterior sites in a $325-550 \mathrm{~ms}$ epoch (Fig. 4). These effects and epochs are consistent with previous reports on processing of VC in normal control subjects, and have been taken to reflect early visual, lexical, and post-lexical stages of word processing. Differential processing of $\mathrm{VC}$ by the Broca patients with agrammatic comprehension as compared to the non-aphasic control subjects was apparent in the 210-325 and $400-700 \mathrm{~ms}$ epochs.

The major finding of the present paper is that the Broca patients with agrammatic comprehension did not show any modulation of the early left anterior negativity (210-325 ms epoch) as a function of VC, whereas the non-aphasic control subjects did. The absence of a VC effect on the early negativity in the Broca patients replicates the findings of our previous study [14]. In the earlier study, however, the open- and closed-class words were presented in a context of prose. The current findings substantiate that the differences between the Broca patients and the non-aphasic control subjects in the early epoch are independent of sentential or lexical context.

\subsection{P2 effects}

Prior to the differences in the $210-325 \mathrm{~ms}$ epoch, all subject groups showed VC effects in the frontal P2 complex (see Fig. 4), with a reduced P2 in the closed-class words. This is consistent with other reports on visual processing of open- and closed-class words as reflected by ERPs $[4,14,15,23,26,27]$. In the very early stages of visual word processing Broca patients with agrammatic comprehension behaved similarly to non-aphasic control subjects.

Early components in the ERP waveforms following stimulus onset are generally taken to reflect the encoding of stimulus features and the initial perceptual processing and categorization of stimulus patterns as faces and letter-strings, rather than the lexical analyses of these patterns (cf. [11]). Furthermore, these components can be sensitive to modulation by visual spatial attention, and particularly P2 components may be highly sensitive to changes of stimulus position (cf. [6]). It is therefore unlikely that the VC effects in this epoch are related to linguistically relevant aspects of open- and closed-class words and of agrammatic aphasia. They are probably due to aspects of the stimuli that are not language-related, such as overall word length differences and/or possible visual-spatial attention effects. 


\subsection{Early vocabulary differences}

In a following epoch, between 210 and $325 \mathrm{~ms}$, clear differences in the processing of VC emerge between the Broca patients and the non-aphasic control subjects. Although in both Broca patients and control subjects a negativity is elicited by the two VCs, only the control subjects show an amplitude modulation of this negativity as a function of VC. The Broca patients do not show this effect. This replicates the findings of our previous study [14].

The negative-going potential that is elicited by the openand closed-class words in this epoch, its modulation as a function of VC, and its topography, largest over left anterior sites, is comparable with previously published reports $[4,14,15,21,23,24,26,27]$. Relative to our previous study in which a prose condition was used, the topography of the VC differences in the present isolated word presentation study is less broadly distributed and largely restricted to left anterior sites.

VC-differences in this epoch have been related to the early stages of word processing in which the lexical-syntactic and lexical-semantic information of a word is accessed and made available for further (sentential) processing $[4,14,15,21,23,27]$. This makes sense given the time course of this effect in relation to the time-course of wordprocessing. This effect is expected to follow the early visual components that are taken to reflect stimulus-encoding and pattern recognition processes such as the N1-P2 complex, but to precede parts of the waveform that are known to reflect post-lexical stages of word processing such as the N400 (cf. [12,18]). The robustness of the early negativity in the electrophysiological profiles elicited by openand closed-class words across context-conditions in our present (isolated word) and previous study (prose) as well as in Münte et al. [21] adds to the evidence suggesting that the early negativity reflects some stage of lexical processing.

Most recent ERP studies on VC differences agree on the fact that the early negativity elicited by the two word classes is probably a manifestation of one and the same underlying process that subserves some aspects of lexical processing. The particular aspect that is reflected is less clear, however, and consequently so are its differences as a function of VC. In our previous study, the absence of any effects of lexical-statistical factors such as word frequency or length on the $\mathrm{VC}$ effect led us to the interpretation that the modulation of the early negativity as a function of $\mathrm{VC}$ is not directly related to lexical access processes. Rather, we have hypothesized that this effect might reflect the first electrophysiological manifestation of the availability of word-category information from the mental lexicon.

In light of the absence of clear length and frequency effects in the present study, we therefore interpret the present results as supportive evidence for our earlier hypothesis that the early VC effects reflect the availability of word-category information from the mental lexicon.
For the Broca patients, the absence of an early VC effect in the present word-list study adds to the evidence suggesting that Broca patients with agrammatic comprehension are impaired in the on-line processing of $\mathrm{VC}$ information at a relatively early stage in word processing. It is highly likely, that irrespective of the particular lexical stage that is reflected by the early negativity, a delay in or incomplete availability of information resulting from lexical processing will not only affect the processing of a particular word itself, but will also affect higher levels of processing, such as sentence comprehension.

On the basis of an absence of the early VC effect we cannot conclude that the impairment in the Broca patients is specifically tied to the processing of closed-class items as has been claimed in several accounts of agrammatic comprehension. The early negativity is elicited by both VCs, it just does not differ as a function of VC.

\subsection{Late vocabulary class differences focusing on the closed-class vocabulary}

A second finding of this study is that the Broca patients with agrammatic comprehension also deviated from the controls in the late part of the waveform for the processing of $\mathrm{VC}$, related to later (post-lexical) stages of word processing. The Broca patients deviated in the 400-700 ms epoch over left anterior sites, relative to the non-aphasic control subjects.

In both the normal control subjects and the non-aphasic $\mathrm{RH}$ patients the closed-class words elicited a negative-going shift between 400 and $700 \mathrm{~ms}$ over left anterior sites. In the RH patients this negative shift was more focal than in the normal controls, but crucially also with a left anterior maximum. In the Broca patients, however, no such shift was elicited. So far, only the recent study by Münte et al. [21] has provided evidence for an N400-700 in word lists, albeit in young normal control subjects.

The morphology of the N400-700 and the late VC effect in the non-aphasic control subjects is comparable with previous reports using sentence or prose conditions $[4,14,15,17,21-24,26,27,29,33]$. As with the early VC effect, the topography of the late $\mathrm{VC}$ effect was reduced relative to the distribution of the effect in our previous prose study. A reduction in the elicitation of the late negative shift by closed-class items was noted in two previous studies in which the presentation of VC was compared across context-conditions (scrambled versus normal prose [27]; word list versus sentence context [21]). This indicates that context may modulate the late negative shift, but is not a prerequisite for its elicitation.

The robustness across context conditions has implications for the functional interpretation of the N400-700. So far, the slow ascending negative shift elicited by closed-class items has generally been classified as a variant of the contingent negative variation under the assumption that readers engage in some form of prediction of upcoming 
structures. This would fit well with the presumed syntactic function of closed-class words, particularly in sentence comprehension. The presence of an N400-700 in a list renders parsing-specific interpretations restricted to phrase level processing unlikely. In Brown et al. [4] and in our previous prose study [14], we suggested, based on the syntactic nature of the closed-class items, that the predictive process involved is due to the general expectation that a closed-class word is followed by a meaningful word. The likelihood of a meaningful word following a closed-class word in this list-experiment is, however, about equal. Hence, this interpretation is also difficult to maintain.

If we still assume that the N400-700 reflects some predictive process, what expectancies might be reflected? As noted by Münte et al. [21], it is quite conceivable that in view of the highly automated and overlearned character of language, many of the usual processing routines would also be engaged in a word-list experiment. Hence, the presence of an N400-700, albeit reduced. The finding by Münte et al. of an N400-700 only for very high-frequency closed-class words, a large proportion being determiners, led them to the hypothesis that different closed-class words might differ in the degree of inherent expectancy that they elicit. Determiners, for example, might entail a higher degree of expectancy because they appear to be more closely linked to a following content word.

For this inherent expectancy to be generated, and its modulation by context, word class information has to be available. The presence of an N400-700 in our study could therefore well be explained along these lines. The majority of the set of closed-class items were very high frequency closed-class words. Moreover, about two-thirds of our set consisted of determiners.

The absence of an N400-700 in the Broca patients makes sense, as suggested by the absence of the early VC effect in these patients, provided that word class information and its inherent expectancy characteristics have not become available to the Broca patients at the same time or to the same degree as to the non-aphasic control subjects. This finding is consistent with the very reduced presence of the N400-700 in the Broca patients in our previous prose study. In prose, the relative lack of lexical-semantic information in the case of a closed-class word may have helped to generate some expectancy for a following meaningful word, as is likely to be the case in prose.

\subsection{Late vocabulary class differences focusing on the open-class vocabulary}

With respect to the (post-lexical) processing of open-class words, we have found no electrophysiological evidence for a difference in processing between Broca patients and their controls. An N400 to open-class words was elicited between 325 and $550 \mathrm{~ms}$ over posterior sites in the three subject groups. This suggests that, just as in the non-aphasic control subjects, Broca patients were able to retrieve lexical-semantic information.

In our previous prose study, no significant N400 effect was found in the non-aphasic control subjects, although a negativity was visible in the waveforms with a morphology and topography that resembled an N400. These differences across context-conditions make sense as each open-class word elicits an N400, but its amplitude is strongly reduced when the word is easy to integrate into sentence or discourse context. The N400 effect in the present word-list study although present is relatively small. This might be due to the relatively low attentional demands of the task [5] and/or to the fact that some items were repeated [32] and/or to the fact that some content words in the lists were semantically related.

Interestingly, in our previous prose study, a significant N400 effect was found in the group of Broca patients but not in the controls. This suggested that the Broca patients experienced difficulties with integrating the lexical-semantic information of the open-class words into the message-level representation of the preceding context. We therefore interpreted these results as consistent with the hypothesis that the word-category information necessary for constructing a phrasal configuration of the sentence did not become fully available to the Broca patients at the right moment in time.

In the present word-list study, there is no need to integrate the lexical-semantic information into the message-level representation of a preceding context. Hence, the absence of electrophysiological evidence for a lexical-semantic processing difference between Broca patients and non-aphasic control subjects.

\section{Conclusion}

By investigating electrophysiological manifestations of on-line processing of open- and closed-class words presented in word lists, this study adds to the electrophysiological evidence suggesting that Broca patients with agrammatic comprehension have an impairment in the on-line processing of word class information.

There were three major findings: (i) the absence of any left anterior modulation of the early negativity as a function of VC in the Broca patients; (ii) the absence of the late left anterior negative shift to closed-class words in the Broca patients and (iii) the presence of an N400 effect in both Broca patients and non-aphasic control subjects. These findings support the view that an incomplete and/or delayed availability of word-class information might be an important factor in agrammatic comprehension of Broca's aphasics.

\section{Acknowledgements}

We wish to thank Dr. Dick Stegeman (Department of Clinical Neurophysiology, Institute of Neurology, University 
Hospital Nijmegen) for his advice, Dr. Peter Praamstra (Department of Clinical Neurophysiology, Institute of Neurology, University Hospital Nijmegen) for helping in selecting and evaluating the CT scans. Furthermore, we wish to thank Marlies Wassenaar, Annemieke Nevejan, and Clarette Blaauw (Max Planck Institute for Psycholinguistics) for their help in screening the neurological patients. This research was supported in part by grant 400-56-384 from The Netherlands Organization for Scientific Research.

\section{References}

[1] Baayen RH, Piepenbrock R, van Rijn H. The CELEX lexical database (CD-ROM). Linguistic Data Consortium. University of Pennsylvania, PA: Philadelphia, 1993.

[2] Berndt RS, Caramazza A. A redefinition of the syndrome of Broca's aphasia: implications for a neuropsychological model of language. Applied Psycholinguistics 1980;1:225-78.

[3] Bradley DC, Garrett MF, Zurif EB. Syntactic deficits in Broca's aphasia. In: Caplan D, editor. Biological Studies of Mental Processes. Cambridge, MA: MIT Press, 1980. p. 269-86.

[4] Brown CM, Hagoort P, ter Keurs M. Electrophysiological signatures of visual lexical processing: open- and closed-class words. Journal of Cognitive Neuroscience 1999;11:261-81.

[5] Chwilla DJ, Brown CM, Hagoort P. The N400 as a function of the level of processing. Psychophysiology 1995;32:274-85.

[6] Clark VP, Hillyard SA. Spatial selective attention affect early extrastriate but not striate components of the visual evoked potential. Journal of Cognitive Neuroscience 1996;8:387-402.

[7] Friederici AD. Levels of processing and vocabulary types: evidence from on-line comprehension in normal and agrammatics. Cognition 1985;19:133-66.

[8] Friederici AD, Kilborn K. Temporal constraints on language processing: syntactic priming in Broca's aphasia. Journal of Cognitive Neuroscience 1989;3:262-72.

[9] Friederici AD, Weissenborn J, Kail M. Pronoun comprehension in aphasia: a comparison of three languages. Brain and Language 1991:41:289-310.

[10] Graetz P, De Bleser R, Willmes K. De Akense afasie test. Lisse: Swets \& Zeitlinger, 1992

[11] Hillyard SA, Teder-Salejarvi WA, Münte TF. Temporal dynamics of early perceptual processing. Current Opinion in Neurobiology 1998;8:202-10.

[12] Holcomb PJ. Semantic priming and stimulus degradation: implications for the role of the N400 in language processing. Psychophysiology 1993;30:47-61.

[13] Huber W, Klingenberg G, Poeck K, Willmes K. Die supplemente zum Aachener aphasie test, aufbau und resultate der validierung. Neurolinguistik 1993;7:43-66.

[14] Keurs ter M, Brown CM, Hagoort P, Stegeman DF. Electrophysiological manifestations of open- and closed-class words in patients with Broca's aphasia with agrammatic comprehension. An event-related brain potential study. Brain 1999;122:839-54.

[15] King, JW, Kutas M. Neural plasticity in the dynamics of human visual word recognition. Neuroscience Letters 1998:1-4.

[16] Kolk HHJ. Disorders of syntax in aphasia: linguistic-descriptive and processing approaches. In: Stemmer B, Whitaker HA, editors. The handbook of neurolinguistics. London: Academic Press, 1997. p. $250-61$.
[17] Kutas M, Hillyard SA. Event-related brain potentials to grammatical errors and semantic anomalies. Memory and Cognition 1983;11: $539-50$.

[18] Kutas M, Van Petten CK. Psycholinguistics electrified: eventrelated brain potential investigations. In: Gernsbacher MA, editor. Handbook of psycholinguistics. San Diego: Academic Press, 1994.

[19] Maxwell SE, Delaney HD. Designing experiments and analyzing data: a model comparison perspective. Pacific Grove, CA: Brook/Cole Publishing Company, 1990.

[20] McCarthy G, Wood CC. Scalp distributions of event-related potentials: an ambiguity associated with analysis of variance models. Electroencephalography and Clinical Neurophysiology 1985;12: 203-8.

[21] Münte TF, Wieringa BM, Weyerts H, Szentkuti A, Matzke M, Johannes S. Differences in brain potentials to open and closed class words: class and frequency effects. Neuropsychologia 2001;39: 91-102.

[22] Neville HJ, Coffey SA, Holcomb PJ, Tallal P. The neurobiology of sensory and language processing in language-impaired children. Journal of Cognitive Neuroscience 1993;5:235-53.

[23] Neville HJ, Mills DL, Lawson DS. Fractionating language: different neural subsystems with different sensitive periods. Cerebral Cortex 1992;2:244-58.

[24] Nobre AC, McCarthy G. Language-related ERPs: scalp distributions and modulations by word type and semantic priming. Journal of Cognitive Neuroscience 1994;6:233-55.

[25] Oldfield RC. The assessment of the analysis of handedness: the Edinburgh inventory. Neuropsychologia 1971;9:97-113.

[26] Osterhout L, Allen M, McLaughlin J. Words in the brain: lexical determinants of word-induced brain activity. Journal of Neurolinguistics 2002;15:171-87.

[27] Osterhout L, Bersick M, McKinnon R. Brain potentials elicited by words: word length and frequency predict the latency of an early negativity. Biological Psychology 1997;46:143-68.

[28] Pulvermüller F. Agrammatism: behavioral description and neurobiological explanation. Journal of Cognitive Neuroscience 1995;7:165-81.

[29] Pulvermüller F, Lutzenberger W, Birbaumer N. Electrocortical distinction of vocabulary types. Electroencephalography and Clinical Neurophysiology 1995;94:357-70.

[30] Rosenberg B, Zurif E, Brownell H, Garrett M, Bradley D. Grammatical class effects in relation to normal and aphasic sentence processing. Brain and Language 1985;26:287-303.

[31] Rösler F, Heil M, Glowalla U. Monitoring retrieval from long-term memory by slow event-related brain potentials. Psychophysiology 1993;30:170-82.

[32] Rugg MD, Doyle MC. Event related potentials and stimulus repetition in direct and indirect tests of memory. In: Heinze H, Münte T, Mangun GR, editors. Cognitive Electrophysiology 1994. p. 124128.

[33] Van Petten C, Kutas M. Influences of semantic and syntactic context on open- and closed-class words. Memory and Cognition 1991;19:95-112.

[34] Van Petten C, Kutas M, Kluender M, Mitchiner M, McIsaac H. Fractionating the word repetition effect with event-related potentials. Journal of Cognitive Neuroscience 1991;3:131-50.

[35] Zurif E, Swinney D, Garrett M. Lexical processing and sentence comprehension in aphasia. In: Carammazza A, editor. Cognitive neuropsychology and neurolinguistics: advances in models of cognitive function and impairment. Hillsdale, NJ: Erlbaum, 1990. p. $123-36$. 